\title{
INFLUÊNCIAS DO CONTROLE ESTRUTURAL NA FORMAÇÃO DE ILHAS E PLANÍCIES DE INUNDAÇÃO NA REPRESA DA USINA HIDRELÉTRICA DO ESTREITO NO RIO TOCANTINS, FILADÉLFIA (TO)
}

\author{
Carlos Augusto Machado ${ }^{1}$ \\ Daniel Araújo Ramos dos Santos ${ }^{2}$
}

\section{Resumo}

As usinas hidrelétricas tem sido a principal intervenção antrópica nos rios brasileiros com impactos no nível de base regional e ajustes morfodinâmicos e morfosedimentares. O objetivo concentrou-se em investigar se as condições estruturais do rio Tocantins, represado pela usina de Estreito têm influenciado na formação de feições deposicionais. A metodologia consistiu da revisão bibliográfica e levantamento de dados matriciais e vetoriais. Posteriormente, no software Qgis 2.18 organizou-se um banco de dados com a criação de composições RGB, utilizadas no mapeamento de feições geomorfológicas e trabalhos de campo para avaliar as feições fluviais mapeadas. Os resultados apontam que as antigas formações fluviais reestruturaram-se na nova dinâmica, com a estabilização de novas planícies de inundação, reativação de paleocanais e diques marginais reconfigurados como ilhas.

Palavras-chaves: Usinas Hidrelétricas; Hidrogeomorfologia; Planície de inundação

\section{INFLUENCES OF STRUCTURAL CONTROL ON THE FORMATION OF ISLANDS AND FLOODPLAINS IN THE ESTREITO DAMN POWER PLANT ON THE TOCANTINS RIVER, FILADÉLFIA (TO)}

\begin{abstract}
The hydroelectric plants have been the main anthropic intervention in brazilian rivers with impacts in the regional base level and morphodynamic and morphosedimentary adjustments. The objective was concentrate to investigate if the structural condition of Tocantins river, dammed by Estreito plant has influenced the formation of depositional features. The methodology consisted in the literature review and survey of matrix and vector data. Posteriorly, in the Qgis 2.18 software a data base was organized with the creation of RGB composition, in mapping of geomorphological features and field woks to assess the river features mapped. The results pointed that the old river formations were restructured in the new dynamic, with stabilization of the new flood plains, paleochannels reactivation and marginal dikes reconfigured as islands.
\end{abstract}

\footnotetext{
${ }^{1}$ Licenciado, Bacharel e Mestre em Geografia pela Universidade Estadual Paulista Júlio de Mesquita Filho (UNESP). Doutor pela Universidade Federal de Uberlândia com a pesquisa intitulada "Gênese e Morfologia de Depósitos Tecnogênicos". Email: delagnesse@ mail.uft.edu.br

${ }^{2}$ Doutorando na Universidade Federal de Goiás, com experiência na área de Geociências, com ênfase em Geografia Física. Mestre em Geografia pela Universidade Federal do Tocantins (2016).
} 
Keywords: Hydroelectric plants. Hydrogeomorphology. Floodplains.

\section{INFLUENCIAS DEL CONTROL ESTRUCTURAL SOBRE LA FORMACIÓN DE ISLAS Y PLANÍCIES DE INUNDACION EN LA REPRESA DE LA HIDROLÉCTRICA DE ESTREITO EN EL RIO TOCANTINS, FILADÉLFIA (TO)}

\section{Resumem}

Las hidroeléctricas han sido la principal intervención antrópica em los rios brasileños com impactos a nivel de base regional y ajustes morfodinámicos y morfosedimentarios. El objetivo fue investigar si las condiciones estructurales del río Tocantins, represado para la central de Estreito, há influído en la formación de las características deposicionales. La metodologia consistió en una revisión bibliográfica y levantamiento de datos matriciales y vectoriales. Posteriormente, en el software Q.gis 2.18, se há organizado uma base de datos con la creación de composiciones RGB, usadas en el mapeo de formatos geomorfológicos y trabajos de campo para evaluar las características fluviales mapeadas. Los resultados muestram que las antiguas formaciones fluviales se reestructuraron e la nueva dinámica, com la estabilización de nuevas planicies de inundación, reactivación de paleocanales y diques marginales reconfigurados como islas.

Palabras-clave: Plantas hidroeléctricas. Hidrogeomorfología. Llanuras de sedimentación.

\section{INTRODUÇÃO}

Responsáveis pela geração de quase $80 \%$ da energia elétrica utilizada no Brasil, as usinas hidrelétricas são, na atualidade, os principais pilares da matriz energética, situação muitas reproduzidas amparada a ideia de "vocação" das regiões hidrográficas (CUNHA, 1995; 2001; COELHO, 2008; BERMANN, 2007). Em perspectiva uma geomorfológica, também é de conhecimento que as UHEs são os principais elementos de desconectividade entre zonas dos sistemas fluviais induzida por atividades antrópicas (STEVAUX; LATRUBESSE, 2017). Desta forma, muitos estudos no mundo têm buscado compreender os impactos diretos que estes empreendimentos podem gerar aos sistemas fluviais, influências reconhecidas em diferentes níveis e escalas espaço temporais (COELHO, 2008; GRISOTTI, 2016).

Em uma perspectiva sistêmica, conforme alguns autores (CUNHA, 1995; BRANDT, 2000; STEVAUX; LATRUBESSE, 2017; WINEMILLER et al., 2016), a regulação do fluxo dos rios pelos barramentos implica diretamente em descontinuidades e ajustes nos processos hidrogeomorfológicos (erosão, sedimentação, transporte, sedimentação). Desta forma, destaca- 
Influências do controle estrutural na formação de ilhas e planícies de inundação na represa da usina hidrelétrica do estreito no rio

Tocantins, Filadélfia (TO)

se que áreas a jusante dos barramentos, apresentam maior variação e modulações na descarga sedimentar pela redução de carga grosseira, modelagem dinâmica de erosão associada diretamente a flutuação da descarga hídrica e modelagem da morfologia do canal. A montante são reconhecidas modificações no balanço hídrico (maior evapotranspiração), maior agradação de material sedimentar e surgimento de unidades morfossedimentares, alteração nos atributos físicos e químicos da água com consequente perca da biota e elevação no nível do lençol freático.

Nesse sentido, o surgimento de estudos científicos versando sobre o conceito hidrogeomorfologia apresenta algumas divergências, mas pode ser sintetizado por Okunishi $(1991,1994)$ citado por Goerl et al (2012) definindo como sendo o estudo entre as interações dos processos hidrológicos e geomorfológicos, mais especificamente a interação entre os sistemas fluviais e de vertente. Dentro deste escopo, os assuntos referentes a esta temática ganham relevo quando enquadrados para o estudo, planejamento e gestão em bacias hidrográficas. Na hidrogeomorfologia, os ambientes morfosedimentares demonstram as modificações da dinâmica fluvial constituindo-se de depósitos de materiais como os paleocanais e terraços segundo Stevaux; Latrubesse (2017) e as unidades apresentam uma forma tridimensional de relevo controlado pela dinâmica de erosão e acumulação do corpo fluvial no espaço e tempo.

No contexto de implantação de usinas hidrelétricas na bacia do rio Tocantins, destacase a UHE de Estreito, como o último grande empreendimento implantado nesta região hidrográfica ao longo de 40 anos, sendo plenamente inaugurada em 2012 (SIEBEN, 2012). Neste sentido, observou-se o surgimento de diversas pesquisas que buscaram entender a reorganização do território em função de funcionamento da UHE (PITOMBEIRA CARVALHO; SIEBEN, 2019; SILVA; SIEBEN, 2019; SIEBEN; CLEPS JUNIOR, 2016), porém, notou-se ausência de trabalhos ou diagnósticos sobre a dinâmica de adaptação dos compartimentos geomorfológicos nesta localidade, tendo em vista que os impactos geomorfológicos amplamente descritos em literatura são casualmente esperados.

Santos; Machado (2018) fizeram uma primeira aproximação para se entender a dinâmica de planícies de inundação no reservatório da UHE de Estreito. Preliminarmente, as análises em campo e de imagens de satélite em alguns locais possibilitaram identificar o papel reliquiar dos diques, padrões de falhas e paleofeições, controlando a conectividade entre as zonas periféricas e centrais no reservatório. Assim, o estudo possibilitou a concepção de hipóteses. 
Primeiramente, considera-se que o surgimento e desenvolvimento de formas e zonas de acumulação no reservatório estão condicionados pelas respostas de fatores intrínsecos (estruturais e morfossedimentares) do vale fluvial as mudanças do nível de base regional geradas pelo reservatório. Desta forma, defende-se que as configurações do fisiografia do vale fluvial submerso ainda exercem influências sobre a geomorfologia do trecho avaliado, em virtude da variação de estilo de canal fluvial, carga sedimentar e diferentes graus de conectividade entre o sistema canal e unidades no vale fluvial afetado. Portanto, o objetivo deste estudo concentrou-se na avaliação dos fatores e processos fluviais que controlam a nova dinâmica atrelada ao represamento, como a formação de ilhas, planícies e barras de sedimentação no médio curso do rio Tocantins.

\section{MATERIAL E MÉTODOS}

Foi realizado o levantamento de informações para a composição de um banco de dados da área de estudo. Utilizaram-se dados bibliográficos e diversas bases vetoriais e raster, organizados e processados no software de geoprocessamento gratuito Qgis 2.18. Informações sobre a aspectos geológicos e geomorfológicos na escala de 1:250.000, foram coletadas no site da Secretaria de Planejamento do Tocantins (SEPLAN, 2004); dados vetoriais da folha Teresina (SB.23) na escala de 1:1.000.000, gerados pela CPRM (2004). Consultaram-se também estudos regionais sobre a evolução tectônica e das linhas de falha da bacia sedimentar do Parnaíba, como CPRM (2001), Crepani; Dias (2004) e Spisila (2005), Saad (1992) Costa et al (1996) e do Instituto de Geografia e Estatística (IBGE, 2011).

Foram selecionadas e coletadas imagens orbitais com média resolução espacial (10 m) para auxiliar a identificação e o mapeamento das feições geomorfológicas presentes antes e depois da formação do lago, sendo utilizadas imagens do satélite Alos, sensor AVNIR 2 de 6 de agosto de 2010 e 24 de setembro 2010, acessíveis gratuitamente no sítio online do IBGE; Modelo Digital do Terreno (MDE), do satélite ALOS World 3D, com resolução de 30m (AW3D30), disponibilizados a partir de 2018 pela JAXA (Japan Aerospace eXploration Agency); imagens do SENTINEL 2B, sensor MSI (multi-spectral instrument) de 5 setembro de 2017. Os dados Sentinel 2 foram adquiridos gratuitamente portal eletrônico Sentinel hub, controlado pela European Space Agency (ESA). Para identificação de feições com maior grau de detalhamento, utilizou-se de imagens do satélite SPOT de 2009 e 2018, que estão disponíveis no programa Google Earth ${ }^{\circledR}$. 
Influências do controle estrutural na formação de ilhas e planícies de inundação na represa da usina hidrelétrica do estreito no rio Tocantins, Filadélfia (TO)

Os dados do Sentinel 2, padrão L2A, já são disponibilizados com correção atmosférica, dispensando, portanto, pré-processamento de dados. No programa de geoprocessamento Qgis 2.18.8, aplicou-se a calibração de histograma e a criação de composições coloridas. A partir da análise das informações geográficas organizadas no SIG, foram feitas a identificação e vetorização de feições geomorfológicas de interesse, como a dimensão do trecho do canal fluvial, paleocanais, delineamento dos antigos diques de inundação e terraços abandonados, e identificação dos processos de readequação desta geoformas pretéritas.

Foram avaliados os aspectos geomorfológicos de 56 exutórios de afluentes de terceira ordem do trecho analisado do rio Tocantins, sendo feita comparações de morfologia, direção de foz e conectividade hidrodinâmica, a partir de interpretações de campo e de imagens Alos de 2010 e Sentinel 2 de 2019. Os canais foram codificados afim de se facilitar a espacialização e organização das informações.

Os trabalhos de campo tiveram como objetivo a verificação e aprofundamento das informações extraídas das imagens de satélite bem como a caracterização e verificação in loco das feições fluviais. Assim, buscou-se também a identificação de processos de degradação ambiental como processos erosivos, desmatamentos e eutrofização.

\section{CARACTERIZAÇÃO DA ÁREA DE ESTUDO}

A área de estudo foi delimitada entre as latitudes $07^{\circ} 24^{\prime} 38^{\prime \prime} \mathrm{S}$ e $07^{\circ} 13^{\prime} 51^{\prime \prime}$; longitudes $47^{\circ} 24^{\prime} 38^{\prime \prime} \mathrm{W}$ e $47^{\circ} 26^{\prime} 29^{\prime}$ W, vide Figura 01, envolvendo um trecho afetado pelo represamento da Usina Hidrelétrica de Estreito. A área definida para o trabalho compreende um trecho de $168 \mathrm{~km}$ de extensão e uma largura média de canal que varia de 0,9 a 3,4 km.

A área de estudo definida para o trabalho compreende um trecho de $170 \mathrm{~km}$ de extensão do rio Tocantins (Figura 1), que se superpõem sobre rochas na porção ocidental da província Parnaíba (Figura 2). A partir do mapeamento de Vasconcelos et al. (2004) e Crepani; Dias (2004), identificou-se nove unidades litoestratigráficas no quadrante delimitado (figura 2) que estão organizados em sequências deposicionais (grupos) que evidenciam a evolução em sinéclise da Bacia Sedimentar do Parnaíba (oeste do Gondwana). 
Figura 1 - Localização da área de estudo no rio Tocantins

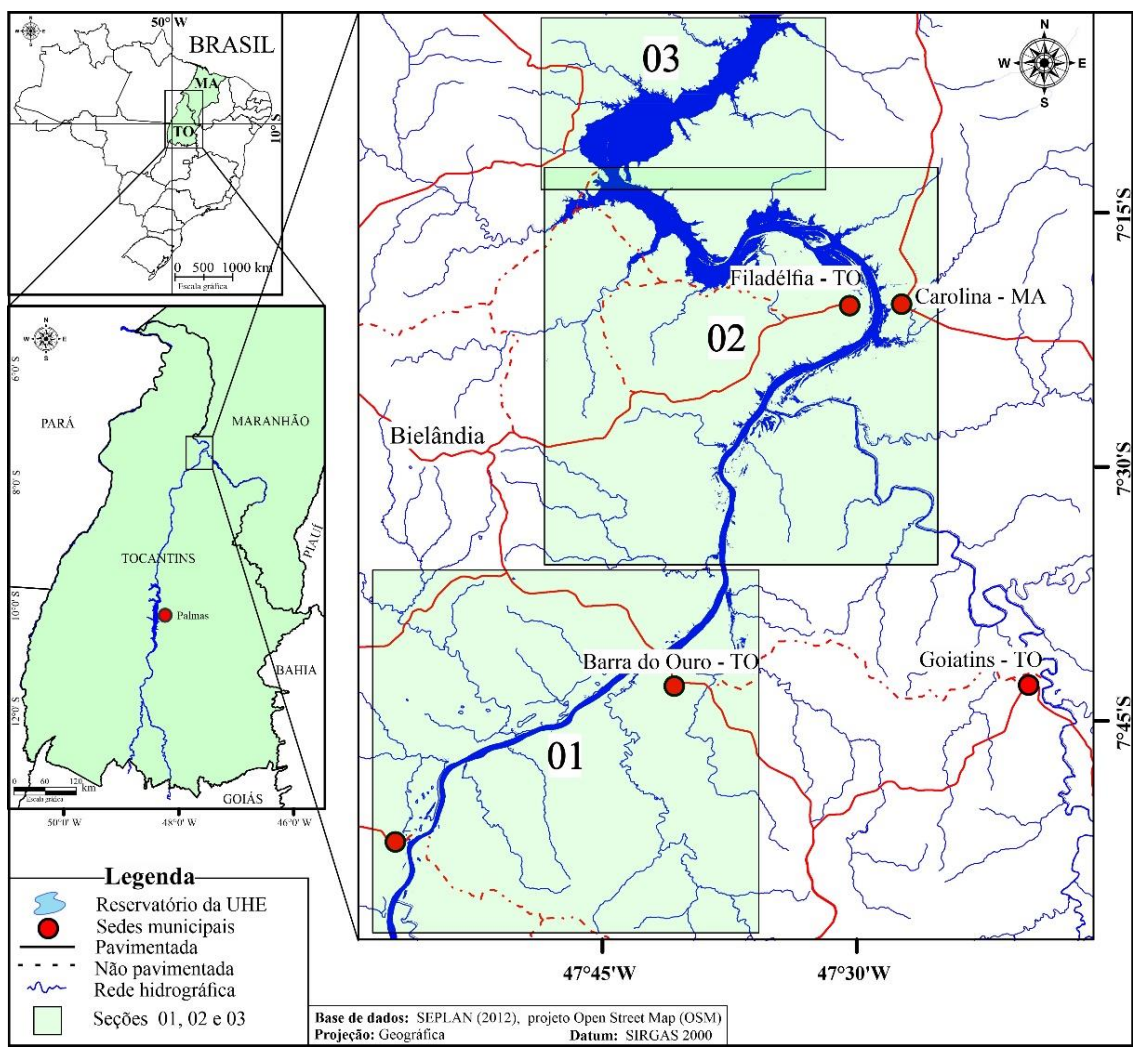

Base de dados: SEPLAN (2012), projeto Open Street Map (OSM)

Elaboração: Autores (2019)

O primeiro agrupamento de unidades, o grupo Canindé é recorrente na porção meridional da área, e corresponde a uma segunda fase de evolução em que bacia sedimentar, paleoambente marinho raso (Figura 2). A formação Longá que compõe a base deste grupo é a unidade litoestratigráfica de idade Devoniana, composta por rochas areníticas creme esbranquiçadas, com granulação fina e grossa, intercalações de siltitos e folhelhos cinzaesverdeados no topo. A formação Poti evidência ciclos deposicionais durante o Carbonífero, em um ambiente deltático e litorâneo, com a recorrência de arenitos de granulação fina e grossa, intercalados por siltitos e folhelhos. 
Influências do controle estrutural na formação de ilhas e planícies de inundação na represa da usina hidrelétrica do estreito no rio

Tocantins, Filadélfia (TO)

Figura 2 - Geologia da área de estudo

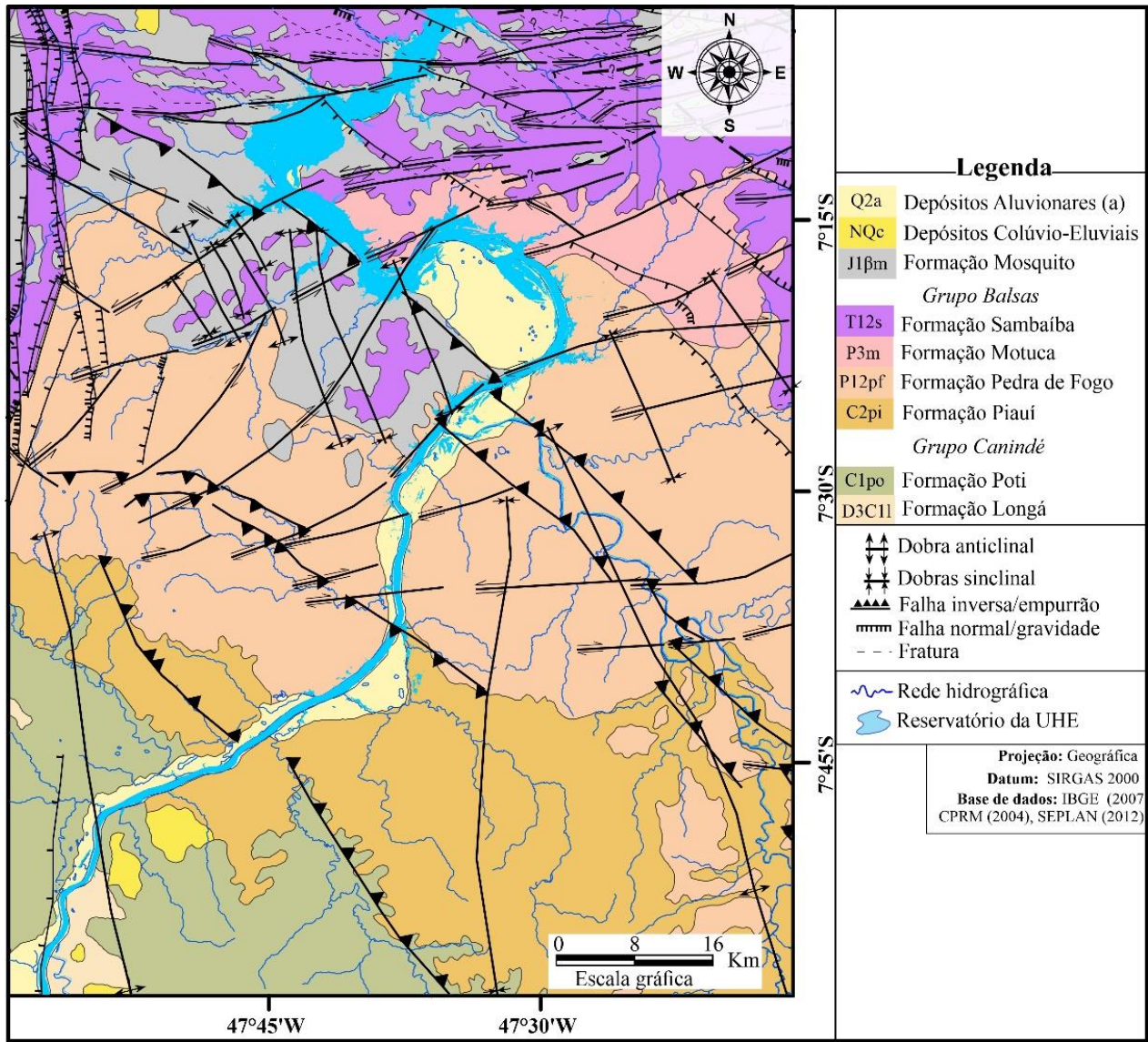

Fonte: IBGE (2007); CPRM (2004); SEPLAN (2017)

Elaboração: Autores (2019)

A Formação Motuca estruturada no período Permiano é composta de rochas sedimentares de origem marinha com estratificação cruzada e intercalações de argilitos e siltitos, tendo sua gênese datada entre 230 e 220 m. resultante de transgressões marinhas na bacia do rio Parnaíba de acordo com Tocantins (2004) e Brasil (2001). Devido à natureza e a granulometria arenosa dos sedimentos e solos desta formação sedimentares que compões os sistemas de chapada e morros testemunhos, aliado ao intenso processo de desmatamento e queimadas na região, pode surgir areais como fontes para o fornecimento de material para o assoreamento dos cursos de água que desembocam na represa do Estreito.

O grupo Balsas se desenvolve sotoposto ao grupo Canindé, estimado com espessura de $1.100 \mathrm{~m}$, reúne litoestruturas relacionadas a fase carbonífero-triássica (III), que foi marcada pela transição de ambiente marinho raso e litorâneo para ambiente desértico e lacustre segundo Vasconcelos et al. (2004). Em sequência sobre a Formação Poti, estabeleceu-se deposições da Formação Piauí, constituída por arenito feldspático com granulação fina e grossa, siltito, 
folhelho e calcário, desenvolvidos em ambiente de fluvial com interações com as transgressões marinhas.

No contato transicional, a Formação Sambaíba de ambiente desértico se estabelece, indicando forte mudança ambiental do continente Pangea durante o Cretáceo, pelo recuo do mar devoniano e instauração de clima de forte aridez. Desta forma, os sedimentos foram reorganizados pela ação eólica em um grande deserto continental, apresentando arenito bimodal com estratificação cruzada de grande porte. Estabelece-se como estrutura de Formação nas porções superiores dos conjuntos de Chapadas, porção Norte e Noroeste da área de estudo segundo CREPANI; DIAS (2004) e CASSETI et al. (2004). Em campo, foi possível observar que devido à retirada da vegetação no talude das chapadas pelo desmatamento e queimadas, os processos de morfogênese se intensificaram aumentando o entalhe do material e desmoronamentos nas bases das encostas, bem como o carreamento de sedimentos.

A Formação Mosquito representa um conjunto de rochas basálticas, relacionadas a derrames de lava durante o Jurássico, que podem ser associadas ao início da separação continental África - América do Sul. O material ígneo recobriu várias áreas da bacia sedimentar sobre formação Sambaíba, com basaltos com variações de cores de cinza-escuro a esverdeado, e características afanítica, constituídos principalmente por plagioclásios e clinopiroxênio e outros minerais acessórios. Os Nitossolos oriundos da decomposição são intensamente usados na agropecuária e na maior parte dos casos sem as práticas de conservação dos solos como terraços e bacias de águas pluviais, que fornecem os sedimentos argilosos e os altos teores de ferro presentes nas ilhas fluviais e planícies de sedimentação.

\section{Geomorfologia Regional}

A unidade Chapadas e Planos do Rio Farinha, popularmente conhecida como "Chapada das mesas", apresenta amplos conjuntos de dissecação estrutural e homogênea, tipicamente tabulares, com altitudes na área avaliada entre 450 e 500m. Autores como Crepani; Dias (2004), Casseti et al. (2004) e Spisila (2011), relacionam o desenvolvimento do relevo desta unidade a fases erosivas pelo recuo paralelo das vertentes em períodos secos e incisão fluvial em períodos úmidos correlacionado com o papel da epirogênica cenozóica, com a superimposição do rio Tocantins as unidades do grupo Balsas e entalhamento de vale em $\mathrm{V}$ na porção norte do rio avaliado, vide Figuras 2 e 3. 
Influências do controle estrutural na formação de ilhas e planícies de inundação na represa da usina hidrelétrica do estreito no rio

Tocantins, Filadélfia (TO)

\section{Figura 3 - Mapa geomorfológico da área de estudo}

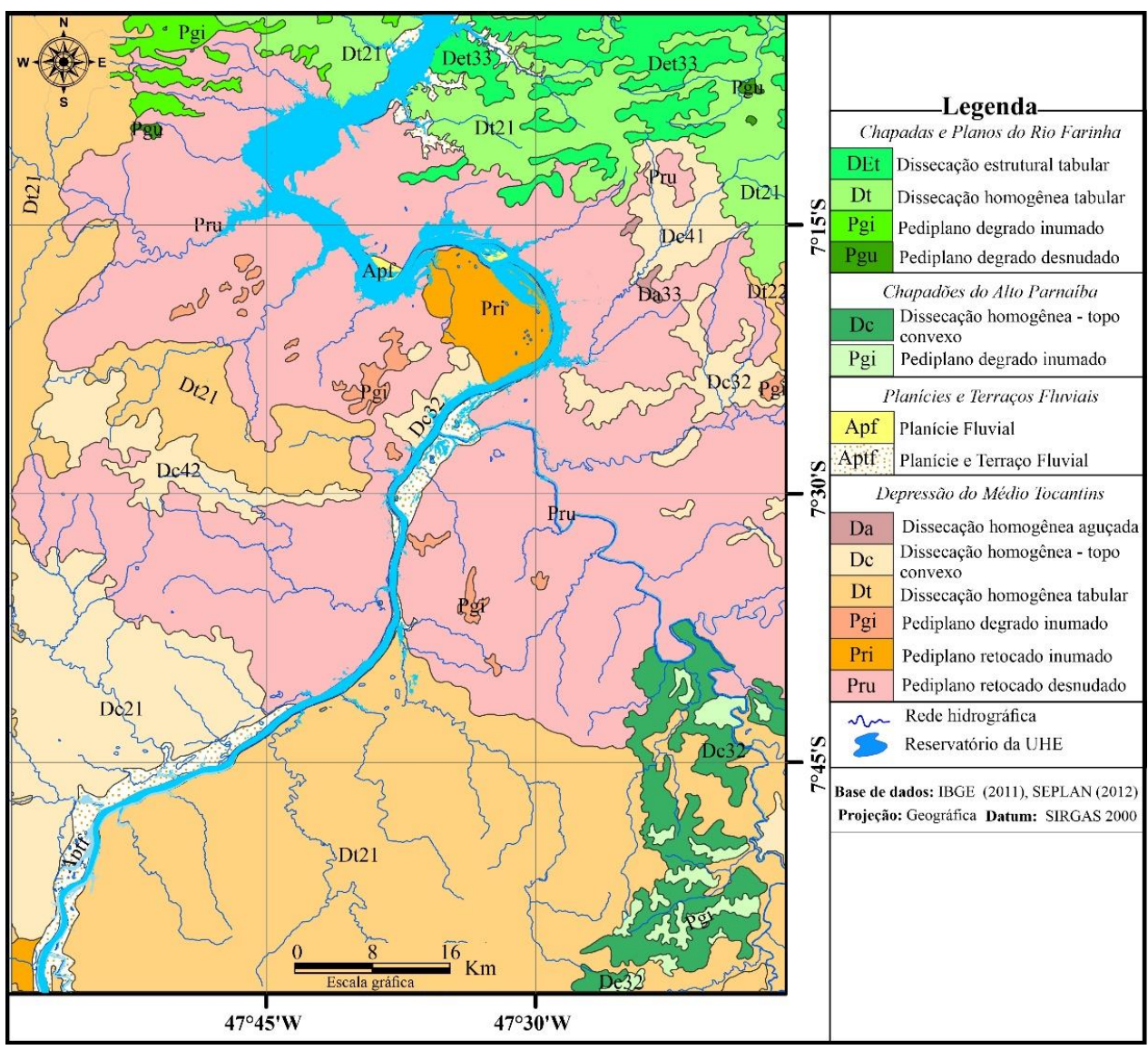

Fonte: IBGE (2011), SEPLAN (2012)

Elaboração: Autores (2019)

A Depressão do Tocantins apresenta-se como a maior unidade geomorfológica da área de estudo e indica modelados resultantes da incisão do rio Tocantins na borda oeste da Bacia do Parnaíba, que promoveu o rebaixamento de compartimentos regionais e exumação de camadas litológicas mais antigas do grupo Balsa, como a Formações Piauí e Pedra de Fogo, com altitudes entre 125 e $250 \mathrm{~m}$.

As unidades mais recentes correspondem aos registros de depósitos colúvios-Eluviais do pleistoceno tardio, composta por sedimentos arenosos, areno-argilosos e conglomeráticos, e o conjunto de depósitos holocênicos aluviais de areia, cascalho e níveis de argila, que são relacionáveis a dinâmica de acreção lateral e vertical pelo rio Tocantins. Segundo Dias et al. (2004), apresentam pelo menos duas fases de soerguimentos, que permitiram forte entalhamento vertical do rio Tocantins sobre as rochas, com a formação de terraços fluviais. 
Figura 4 - Contato entre Escarpas das "Chapadas da Mesa" (segundo plano); modelados de dissecação suave na Depressão do Tocantins (primeiro Plano), Bielândia (TO)

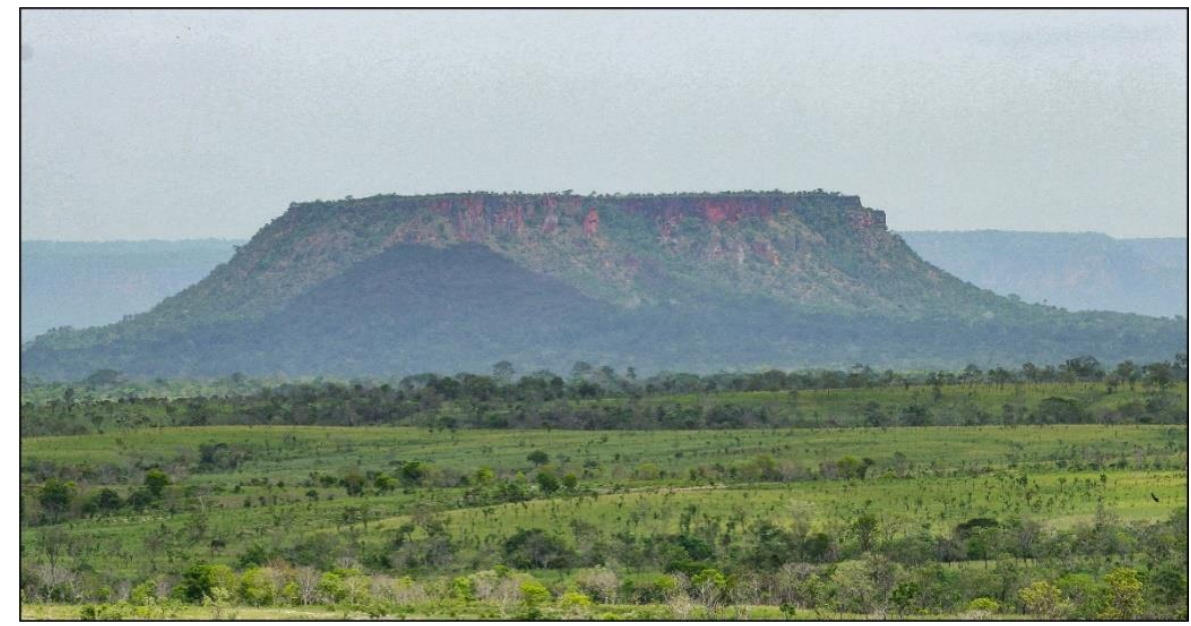

Fonte: Autores (2018)

A análise de direção dos 256 lineamentos definido pelo IBGE (2011) e Vasconcelos (2004) indica que 15\% deste estão alinhados no eixo ENE-WSW, sendo associados por alguns autores ao controle do Lineamento Tianguá-Carolina ou sistema Carolina-Pedra Caída, que é composto em sua maioria por falhas transcorrentes dextrais. Trucando estas estruturas, levantou-se que $14 \%$ dos lineamentos estão orientados no eixo NW-SE. Estes dois padrões são confirmados na análise de Spisila (2011), que indicou quatros fases de deformação estabelecidas no Permiano, Triássico, Jurássico e Cretáceo.

\section{DISCUSSÃO E RESULTADOS}

Processos e fatores geomorfológicos relacionados à formação das ilhas e das planícies de inundação no médio rio Tocantins

Com a finalidade de aprimorar a análise das características e mudanças geomorfológicas e ambientais na área de estudo, dividiu-se o canal principal em três seções, definidas pela correlação entre aspectos geomorfológicos, geológicos e topográficos da área (Figura 1).

A seção 01 compreende um trecho de $59 \mathrm{~km}$, iniciando próxima a cidade de Palmerante até as proximidades dos exutórios dos rios Amaro (ponto 01- Extrema; Ponto 19 na Figura 5). Esse trecho apresenta-se encaixado sobre os domínios litoestruturais do Grupo Canindé e da Depressão do Tocantins, controlado por falhas normais. Desta forma, é possível inferir pela tipologia e orientação dos trechos de canal, que existe uma relação de encaixamento do fluxo principal sobre o bloco rebaixado. Nota-se que o canal muda de direção a partir do ponto 07 apresentando fuga de controle associado ao lineamento Tocantins e flui acompanhando a 
Influências do controle estrutural na formação de ilhas e planícies de inundação na represa da usina hidrelétrica do estreito no rio

Tocantins, Filadélfia (TO)

tendência regional de mergulho das camadas da borda oeste da Bacia do Parnaíba (NE) em um padrão consequente entalhando seu vale sobre rochas friáveis e novamente reorientado por conjuntos transcorrentes no quadrante NE para sentindo NW (Figura 2) (COSTA et al., 1996).

Figura 5 - Mapa com localização dos exutórios dos tributários do rio Tocantins avaliados e feições geomórficas mapeadas na seção 01 da área de estudo

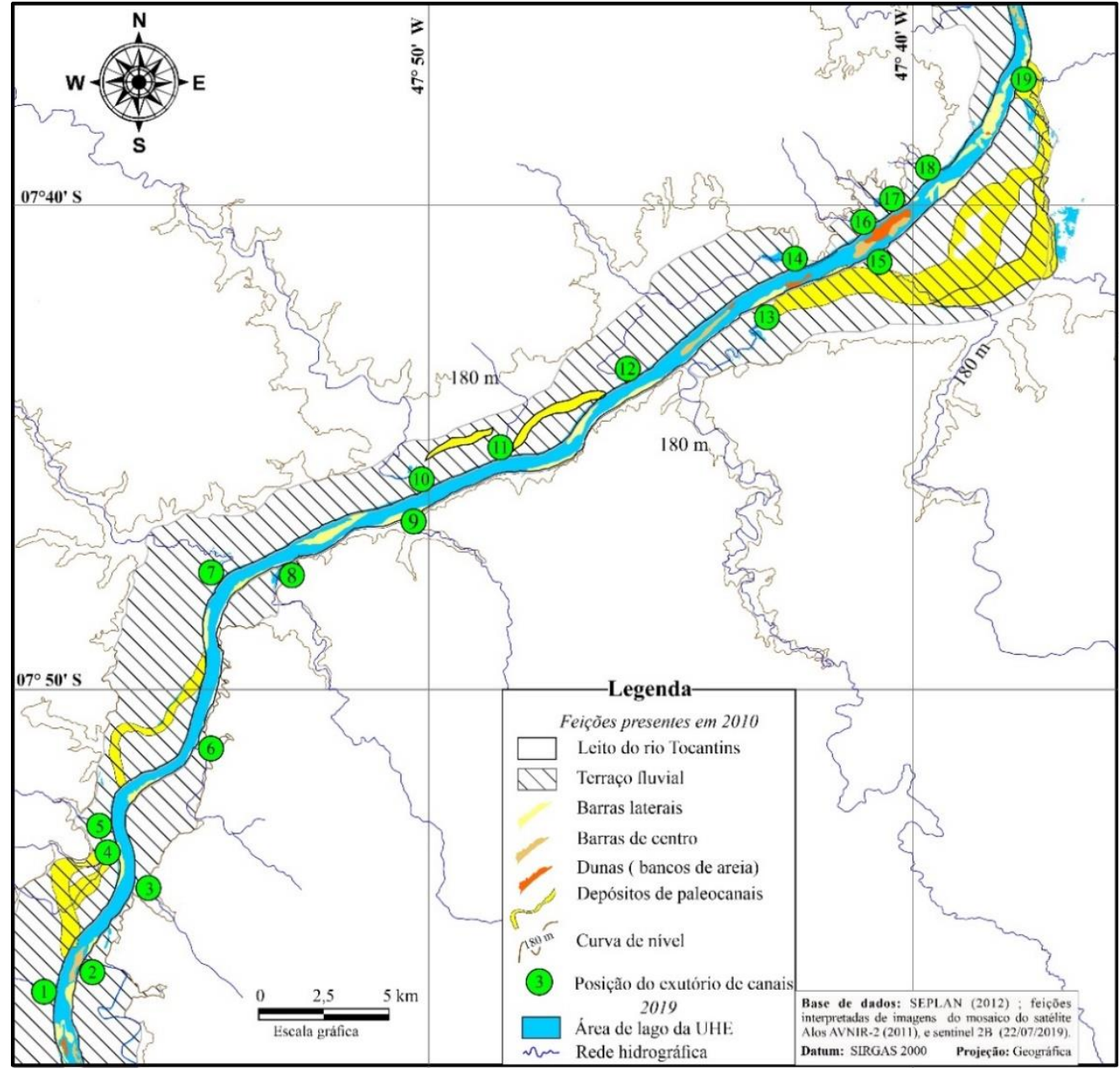

Fonte: Autores (2019)

O mapeamento geomórfico do vale fluvial apresentou extensas unidades morfosedimentares que podem ser associadas às mudanças verticais e laterais no talvegue do segmento, ocorrendo uma relação entre o ajustamento perfil longitudinal com o desenvolvimento lateral e horizontal de modelos geomórficos. Entre as unidades destaca-se as dimensões dos conjuntos de paleocanais que apresentam um grau de sinuosidade mais elevado, quando comparado ao canal ativo que alterna seu padrão com cotovelos, como no caso do segmento entre os pontos 01 e 07 que possui baixa sinuosidade $(1,2)$ conduzida por desvios suaves das linhas de fluxos em virtude dos depósitos recentes (barras). Entre os pontos 07 e 13, 
nota-se um padrão retilíneo é marcado por baixa sinuosidade e surgimento de barras e bancos de areia no centro do canal. Em sequência, entre os pontos 13 e 18, o trecho de linearidade é interrompido por curva acentuada, que apresentas fases de encurtamento (chute-off) no passado da drenagem, ocorrendo também a readaptação dos tributários aos paleocanais da margem direita (Figura 5).

Em 2010, todos os tributários avaliados apresentavam uma conexão direta de seus fluxos ao rio Tocantins. Com a formação do reservatório, novas tipologias foram identificas em resposta a mudanças no nível de base regional e do controle litoestrutural das unidades morfosedimentares. No caso da seção 01 que apresenta 19 tributários, vide Figura 5, notou-se a posição dos exutório sobre os terraços em níveis superiores a planície, o que possibilitou a conservação $43 \%$ da classe de conexão direta.

A classe de lago semifechado compreende 53\% em 2019, o que representa os exutórios que foram afetados verticalmente e lateralmente, porém, com preenchimento da planície de inundação e conexão ao lago principal restrita ao talvegue original do tributário (Figura 6). Em menor representatividade nesta seção, a classe de lagos abertos também apresenta exutórios afetados lateralmente e verticalmente, mas com conexão ampla e livre dos fluxos ao lago principal.

Figura 6 - Imagens de satélite Sentinel 2 de 2019, representando os tipos de conexões dos tributários ao reservatório da UHE Estreito.

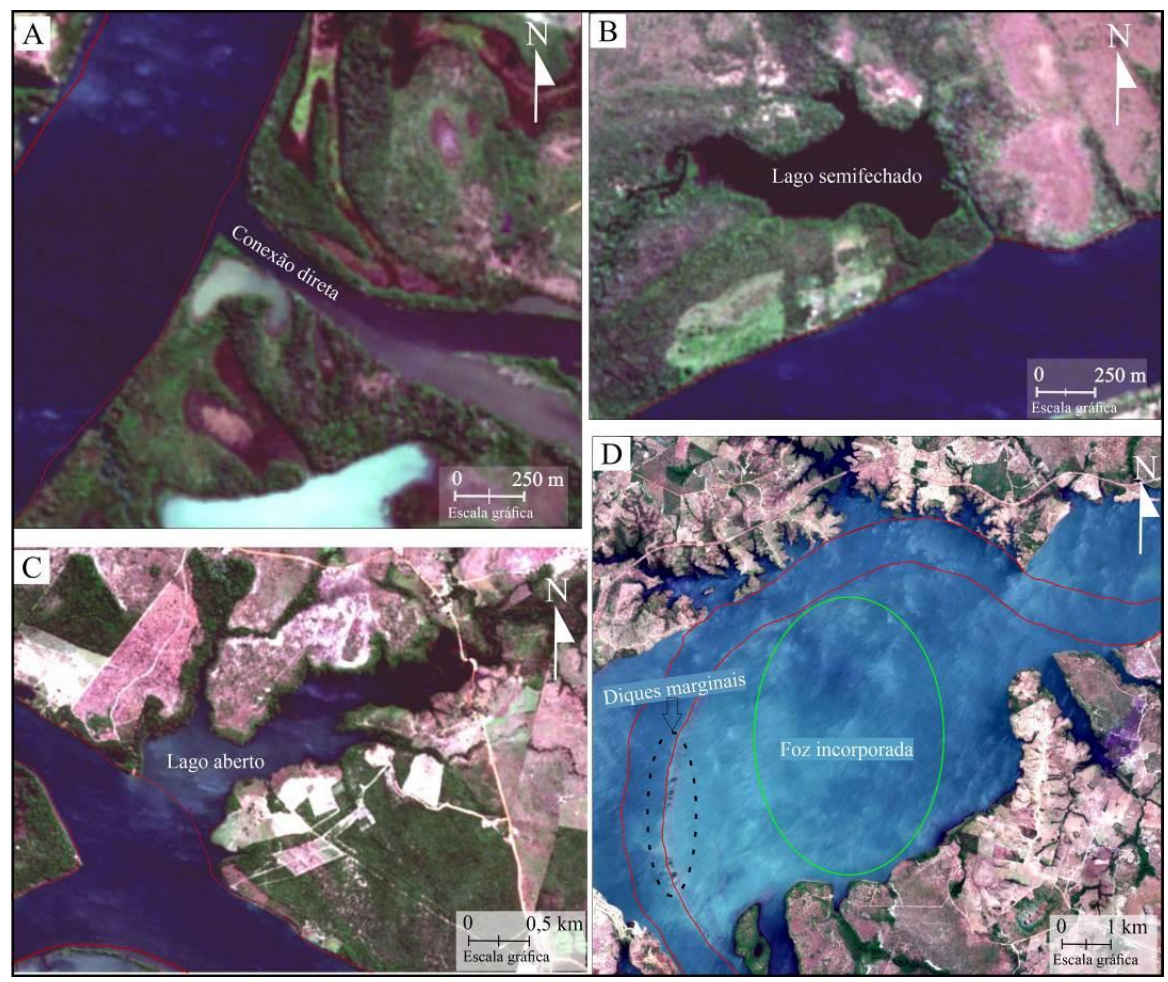

Fonte: Google Earth (2019) 
Influências do controle estrutural na formação de ilhas e planícies de inundação na represa da usina hidrelétrica do estreito no rio

Tocantins, Filadélfia (TO)

Assim, como na seção 01, as feições deposicionais mapeadas na seção 02 (Figura 7) foram recobertas pelas águas do reservatório, chegando aos terraços fluviais. Uma das mudanças promovidas neste setor foi a reativação de paleomeandros a condições de drenagens readaptadas ou sistemas de lagos isolados sobre os terraços. As observações das imagens ALOS e cartas geológicas indicam uma grande ilha de sedimentação no centro do canal, denominada de ilha do Boto, com gênese relacionada a processos fluviais na qual predominam depósitos aluvionares. Essa feição típica do rio Tocantins apresentava até 2010, um padrão tridimensional com extensão longitudinal de 4,6 km e latitudinal de $1,9 \mathrm{~km}$, com topografia de 148 metros e uma parte frontal estabilizada em virtude da vegetação. Na Figura 10 foi possível identificar ainda paleocanais no centro desta ilha. A disposição de orientação e aspectos úmidos destas feições marcam os paleocaminhos do fluxo, e a morfologia abalonada do canal principal está associada a estagnação do material no centro, o que reorientou os fluxos para as laterais provocando o alargamento pontual das margens. Os paleocanais estão orientados no eixo SENW, preenchidos rapidamente pela carga de fundo do rio e abandonados pela bifurcação lateral do canal. A reativação de paleocanais por elevação do nível de base em reservatórios em outras partes do país é demonstrada em estudos com o de Rocha et al. (2008).

Figura 7 - Mapa com localização dos exutórios dos tributários do rio Tocantins avaliados e dos conjuntos geomórficos mapeados na seção 02 da área de estudo

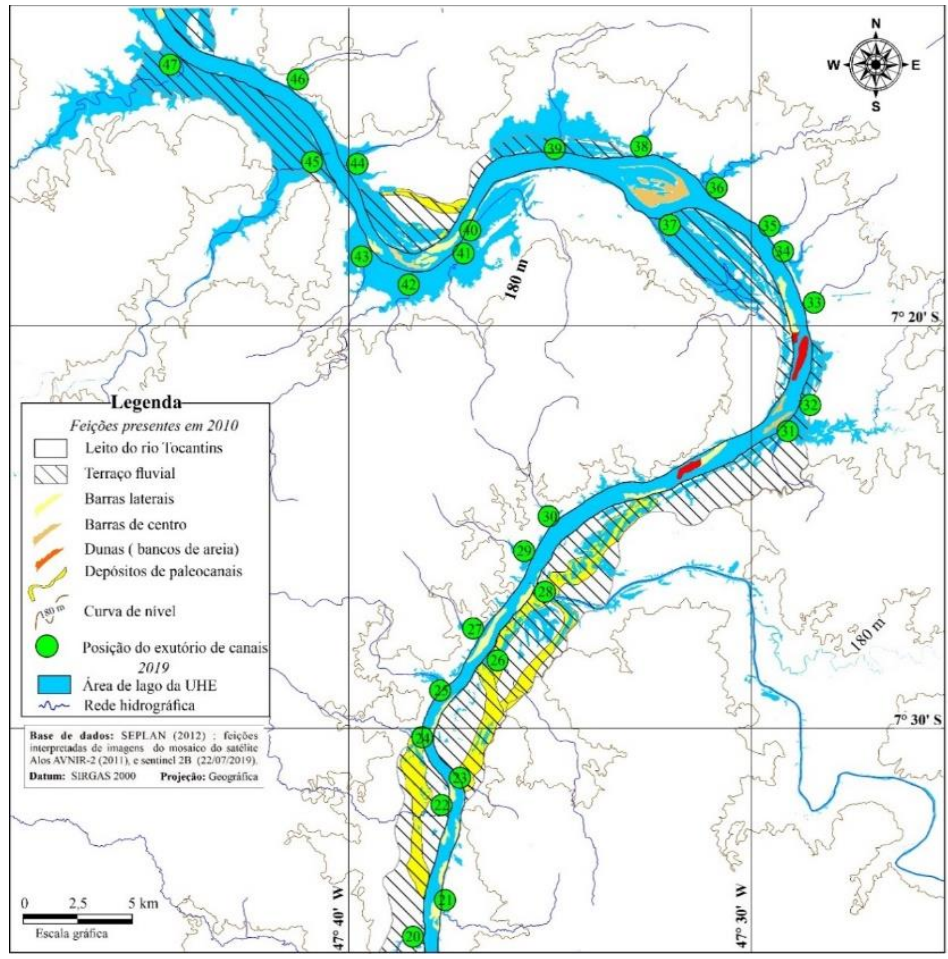

Elaboração: Autores (2019) 
A seção 02 corresponde ao segmento de canal ajustado as condições geomórficas estabelecidas pelas litoestruturas do grupo balsas na depressão do Tocantins com maior abertura do vale e desenvolvimento de planície de inundação do que a seção anterior (Figura 9). Delimitou-se um trecho com $79 \mathrm{~km}$ de comprimento com distância vetorial de $45 \mathrm{~km}$, com sinuosidade média de 1,7, o que em tese identifica-se tipo padrão de canal meandrante (CHRISTOFOLETTI, 1980). Entretanto, para Stevaux; Latrubesse (2017), somente este índice não é suficiente para tal associação, tendo em vista que se deve considerar o contexto de interrelação de fluxo-composição do canal em relação aos aspectos litoestruturais e geomorfológicos. Assim, conforme estes autores, o canal apresenta característica de padrão sinuoso encaixado e orientado pelo controle estrutural do grupo Balsas, vide Figura 2, que apresenta lineamentos regionais com direção e configuração geomorfométricas análogas a direção do sistema fluvial.

A análise das condições morfológicas dos canais e de conectividade hidrodinâmica de seu exutórios (Tabela 1 e Figuras 6 e 7) indica que os exutórios dos tributários com padrão sinuoso e com conexão direta, foram morfologicamente reconfigurados a uma posição de lagos semifechados (39\%). Assim como já observado na seção 01 (Figura 6), os tributários da seção 02 (Figura 8) desenvolviam seus segmentos finais sobre os terraços e planície fluvial de forma predominantemente sinuosa. Notou-se que o a cota do lago chegou a planícies pelo os exutórios dos tributários, porém, sem recobrir diques marginais, que mantem um certo tipo de isolamento a zonas de diferenciação energética no reservatório da UHE. A classe de "Área incorporada ao lago" surge nesta seção a partir do ponto 37 , correspondendo a $32 \%$ dos tributários que tiveram fortes mudanças, com cobrimento total da foz.

Ao considerar todas as seções detectou-se que ocorreu pouca ocupação lateral das áreas adjacentes ao canal na porção sul pelo represamento da UHE, sendo que o canal está encaixado nas rochas sedimentares do grupo Canindé com forte desnível da planície de inundação (CPRM, 2004), vide Figura 1. Na parte média da seção 02 nota-se que a cota de enchimento do reservatório ocupou parte das planícies fluviais que eram formadas por áreas rebaixadas na planície de inundação, reativando paleocanais que acumulavam água no período de cheia e gerou áreas residuais ocupadas por uma densa vegetação.

A seção 03 é a menor mapeada com $28 \mathrm{~km}$ de comprimento de canal e distância vetorial de $23 \mathrm{~km}$ (Figura 8). Esse segmento apresenta duas sequências de canal sinuoso com índice de 1,2. Apresenta forte imposição tectônica cenozoica do canal que se encaixa superimposição da 
Influências do controle estrutural na formação de ilhas e planícies de inundação na represa da usina hidrelétrica do estreito no rio

Tocantins, Filadélfia (TO)

drenagem as condições das rochas areníticas do grupo Balsas e basaltos da Formação Mosquito, modelando um vale profundo margeado por escarpas erosivas das chapadas das Mesas. Esta configuração da morfologia do trecho se assemelha a descrição de padrões Psamítico, como descrito em trechos do Colorado no Estado Unidos e do São Francisco (Bahia-Brasil) (BIGARELA et al., 2007; CHRISTOFOLETTI, 1980).

Figura 8 - Mapa com localização dos exutórios dos tributários do rio Tocantins avaliados e dos conjuntos geomórficos mapeados na seção 03 da área de estudo

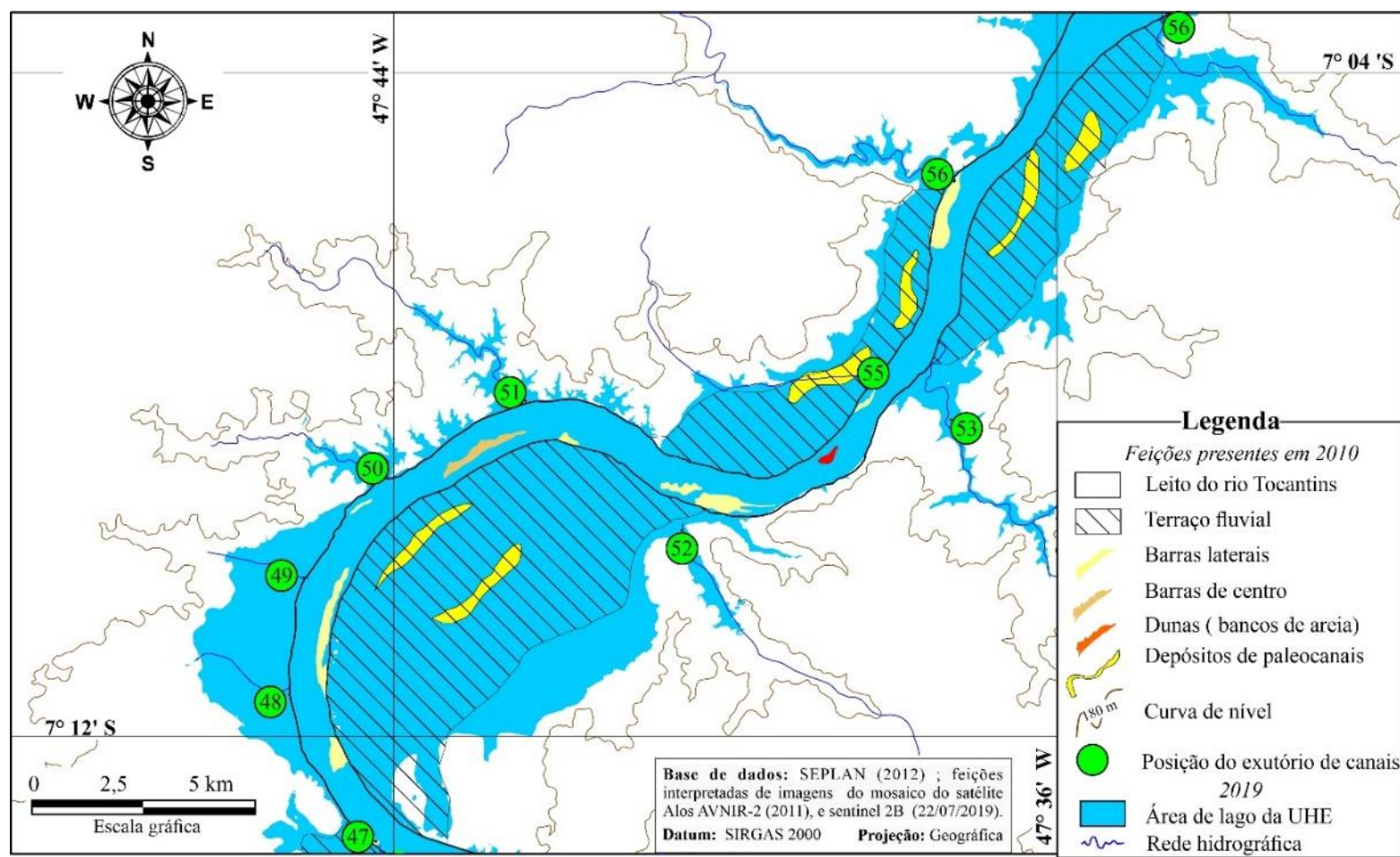

Elaboração: Autores (2019)

Os tributários da seção 03 possuíam predominantemente morfologia do exutório com trecho sinuoso/tortuoso, padrão controlado pelos cordões de meandros nos terraços e na planície aluvial, que podem apresentar resistência e controlar a direção do canal no terraço ou planície fluvial. Nesta seção, nota-se grande área da curva que foi tomada pelas águas do reservatório (Figura 9B), com a parte de baixo dos tributários (entre 47 e 56) afetados, sendo 90\% dos exutórios incorporados ao reservatório (Figura 8). 
Figura 9 - Imagens Spot de alta resolução paleocanais (A) e de diques (B)
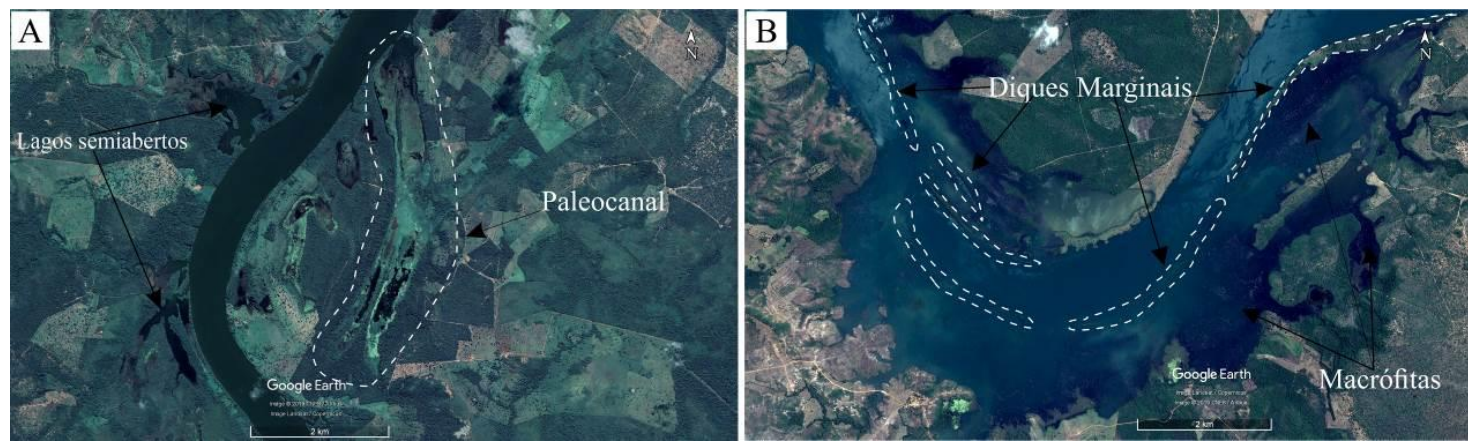

Fonte: Google Earth (2019)

Nota-se que resquícios dos antigos diques do rio Tocantins permanecem delimitando uma zona de contato do antigo canal do rio Tocantins, na qual a conexão dos rios com o reservatório ocorre por trechos estreitos e baixa movimentação fluvial (Figura 10).

As porções não ocupadas pelas águas do reservatório correspondiam os diques marginais, vide Figura 7 (entre os pontos 33 e 38), em destaque nas fotos da Figura 10, indicam a posição das antigas margens do leito do rio Tocantins, que atualmente correspondem a barras residuais, delimitando todo o antigo leito do rio (traçado nos mapas das Figuras 5, 7 e 8). A composição colorida de bandas da faixa do visível (2B;3G;4R) permitiu identificar zonas com maior profundidade com tons em azul escuro que marcam o talvegue do antigo canal, que apresentam trechos com maiores velocidades de deslocamento do fluxo (Figura 6). 
Influências do controle estrutural na formação de ilhas e planícies de inundação na represa da usina hidrelétrica do estreito no rio

Tocantins, Filadélfia (TO)

\section{Figura 60 - Diques residuais do antigo leito do rio Tocantins}

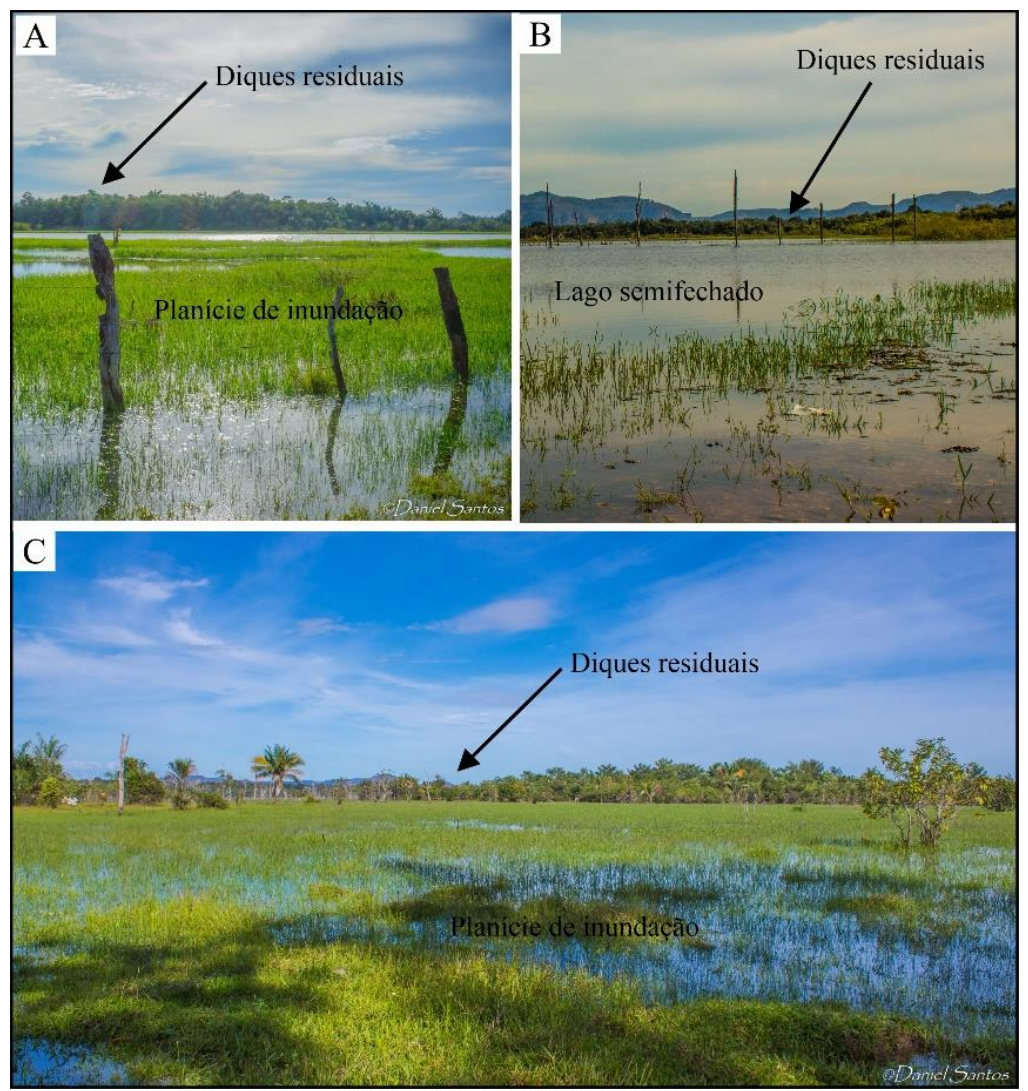

Fonte: Autores (2018)

Nos ambientes com menor profundidade e com menor disposição energética ocorrem áreas rasas nas margens com tons azuis marinos (Figura 7). As novas barras de sedimentação derivadas dos diques marginais próximas a cidade de Filadélfia, vide Figura 10, possuem formas alongadas em arco no sentido SE-NW com extensão superior à $7 \mathrm{Km}$, apresentando cotas altimétricas situando-se entre 158 e 160 metros de altitude intercaladas por canais com profundidade máxima de 4 a 9 metros de acordo com os dados topográficos.

As análises dos dados de imagens de satélite no período de 2013-2016 permitem inferir que existe uma tendência de estabilização de planície de inundação próxima a cidade de Filadélfia, pois o rio Tocantins não conseguiu romper os antigos diques marginais que desenvolveram sobre as coberturas detrítico-lateríticas. Na margem esquerda, os diques também isolaram as drenagens existentes que se conectava diretamente ao rio Tocantins (Figura 7, ponto 37).

A elevação do nível das águas e avanços laterais tem promovido ainda uma série de mudanças nas encostas, podem estar relacionadas a questões pedogenéticas e hidrogeológicas. 
Em campo, observou-se principalmente na margem direita que nas encostas mais íngremes da Formação Sambaíba, os processos erosivos das margens pelo solapamento da base pelas das águas da represa é mais intenso devido aos frágeis solos de textura arenosa (Neossolos quartzarênico e Latossolos), que desprovidos de vegetação fornecerão uma grande carga de sedimentos a serem depositados e estabilizados na nova planície.

Com o surgimento de novas ilhas fluviais, dunas subaquáticas, planícies de inundação e o trabalho de erosão das margens indicam que o rio Tocantins teve um aumento de carga sedimentar em função de mudanças na dinâmica da paisagem, como desmatamentos associados às constantes queimadas na época de estiagem (junho-outubro) e de abertura de novas áreas agrícolas, o que pode potencializar os processos erosivos destas áreas nos próximos anos.

\section{CONSIDERAÇÕES FINAIS}

A análise dos lineamentos estruturais indica uma concentração das falhas e fraturas em duas direções preferenciais na área avaliada, com forte correlação entre controle estrutural e reorganização da direção e evolução de padrão de canal do rio Tocantins, o que segundo Costa et al. (1996), é evidenciado pela instalação de padrão retangular dos sistemas fluviais, cotovelos e curvas abruptas controladas pelas falhas transcorrentes.

A avaliação geomórfica indica que em longo termo a migração lateral foi interrompida por fases de maior incisão do canal, abandono da planície de inundação e com a geração de terraços fluviais de grande extensão, agora ocupados pelas águas do reservatório.

Esta mudança de padrão favoreceu o aparecimento de grandes planícies de inundação e diversas ilhas próximas à cidade de Filadélfia e Babaçulândia e que mesmo com a formação do reservatório da Usina Hidrelétrica do Estreito continuam ainda com um grande processo deposicional de sedimentos pelo rio Tocantins e dos afluentes em ambas as margens e que aliado à uma forte eutrofização verifica-se a estabilização da planície de sedimentação e a formação de ilhas.

A avaliação das feições geológicas e geomorfológicas em apenas uma década de enchimento do lago da UHE, demonstra a importância da influência das linhas de falha na formação de áreas inundadas com importância ecológica para a reprodução das espécies e a importância de se desenvolver um estudo de longo prazo para verificação da efetivação dos processos. A priori, pode-se considerar que:

A influência das linhas de falhas no médio curso do rio Tocantins alterando o padrão retilíneo para curvas acentuadas diminuiu a capacidade de transporte de sedimentos e favoreceu 
Influências do controle estrutural na formação de ilhas e planícies de inundação na represa da usina hidrelétrica do estreito no rio

Tocantins, Filadélfia (TO)

o aparecimento de novas planícies de inundação e formação de novas ilhas. As ilhas, praias e barras de sedimentação constituíam para a população ribeirinha espaços econômicos para a plantação de diversos produtos alimentícios e devido à dinâmica de inundação periódica que fertilizava todo ano estas áreas, bem como a prática da pesca de subsistência.

Além deste fato ocorria o uso das praias para lazer e de férias para a população da região através da qual os moradores eram empregados em diversas atividades constituindo uma fonte de renda essencial para a manutenção da família. Com a nova configuração ambiental elaborando novas ilhas e outras formas fluviais, estes espaços atualmente não podem ser ocupados devido à região ter se tornado área de preservação ambiental, fiscalizada continuamente evitando a instalação de moradias.

Vale ressaltar que o processo de retirada dos moradores teve o pagamento de indenizações mínimas e a realocação desta população de pescadores e agricultores de sistema de vazante para áreas de até $30 \mathrm{~km}$ distantes do rio, em locais com água subterrânea salobra, solos distróficos (Neossolos quartzarênico) comprovados em trabalhos de campos e analisados pode diversos estudos da Universidade Federal do Tocantins (UFT).

\section{REFERÊNCIAS}

ANA - Agência Nacional de Águas Bacia do Tocantins. Disponível em: <http;//.ana.gov.br/Bacias/Tocantins/caracgeral/osrecursos/.>Acesso em 18 set. 2012.

ANEEL - Agência Nacional de Energia Elétrica Atlas da energia elétrica do Brasil. 2. ed. Brasília: ANEEL, 2005. 243 p.

ANJOS, C. E.; DIAS, R. R. 2004. Geologia da Folha SB.23-Y-C (Carolina) - Estado do Tocantins. Projeto de gestão ambiental integrada da região do Bico do Papagaio - Zoneamento sócio econômico. SEPLAN/DZE. Palmas - TO. 52p.

BERMANN, C. Impasses and controversies of hydroelectricity. Estud. av., São Paulo, v. 21, n. 59, p. 139-153, Apr. 2007.

BRANDT, S. A. Classification of geomorphological effects downstream of dams. Catena, v. 40, n. 4, p. 375-401, 2000.

CARVALHO, G. A. P.; SIEBEN, A. Da ilha de São José ao reassentamento coletivo Baixão em Babaçulândia: efeitos da Usina Hidreléctrica de Estreito na Amazônia. Cuadernos de Geografía: Revista Colombiana de Geografía, v. 28, n. 1, p. 175-191, 2019. 
CHRISTOFOLETTI, A. Geomorfologia Fluvial. São Paulo: Edgar Blucher Ltda, 1981. 313p.

COELHO, A. L. N. Geomorfologia fluvial de rios impactados por barragens-Fluvial. Caminhos de Geografia, v. 9, n. 26, 2008.

COSTA, J. B. S.; BEMERGUY, R. L.; HASUI, Y; BORGES, M. DA S.; FERREIRA JUNIOR, C. R. P.; BEZERRA, P. E. L.; COSTA, M. L. DA; FERNANDES, J. M. G. 1996. Neotectônica da Amazônia: aspectos tectônicos, geomorfológicos e deposicionais. GEONOMOS, Revista de Geociências. 4: (23-44p).

CPRM 2001. Programa Levantamentos Geológicos Básicos do Brasil - Escala 1:250.000. CPRM - Serviço Geológico do Brasil. Brasília - DF: CPRM/DIEDIG/DEPAT.

CREPANI, E.; DIAS, R. R. 2004. Geologia da Folha SB.22 - X - B (Tocantinópolis) - Estado do Tocantins. Projeto de gestão ambiental integrada da região do Bico do Papagaio Zoneamento sócio econômico. SEPLAN/DZE. Palmas - TO. 46p.

CUNHA, S. B. Geomorfologia Fluvial. In: GUERRA, A.J.T.; CUNHA, S.B. (orgs.) Geomorfologia uma Base de Atualização e Conceitos. 4. ed. Rio de Janeiro: Bertrand Brasil, 2001. p. 211-252.

FELIPE, L. B.; MORALES, N. Influência Neotectônica na Evolução Geomorfológica e Geológica da Região de Marabá - PA. In: LIMA, A. M. M.; GORAYEB, P. S. de S. (Org.). Contribuições à Geologia da Amazônia - Volume X. 1ed.Belém: Sociedade Brasileira de Geologia, 2017, v. 10, p. 1-446.

GOERL, R. F.; KOBIYAMA, M.; SANTOS, I. dos Hidrogeomorfologia: princípios, conceitos, processos e aplicações. Revista Brasileira de Geomorfologia, v.13, n.2, (Abr-Jun) p.103-111, 2012

GRISOTTI, M. A construção de relações de causalidade em saúde no contexto da hidrelétrica de Belo Monte. Ambiente \& Sociedade, São Paulo, v. 19, nº 2.

MORAN, E. F. Roads and Dams: Infraestructure-driven transformations in the Brazilian Amazon, In: Ambiente \& Sociedade, São Paulo, vol.19, nº 2, 207-220, Jun 2016.

OLIVEIRA, N. C. C. A grande aceleração e a construção de barragens hidrelétricas no Brasil. Varia História, Belo Horizonte, v. 34, n. 65, p. 315-346, Aug. 2018.

ROCHA, P. C. ; BOMBONATO, A. C. ; SILVA, L. DE M. ; BRANDÃO, F. ; ANDRADE, I. R. A. de Geomorfologia e Reativação de Paleocanais em Uma Área de Influência do Reservatório da U.H.E. Porto Primavera, Planície do Rio Paraná, Centro-Sul do Brasil. IN: Anais do VII Sinageo / II Encontro Latino-Americano de Geomorfologia, 2008, Belo Horizonte-MG. anais do VII Sinageo, 2008. 
Influências do controle estrutural na formação de ilhas e planícies de inundação na represa da usina hidrelétrica do estreito no rio Tocantins, Filadélfia (TO)

SANTOS, D. A. dos ; MACHADO, C. A. . Novas dinâmicas hidrogeomorfológicas na represa da Usina Estreito no rio Tocantins. In: Rivers, Lands and Cultures: Learning from the Tocantins Social-ecological system, 2018, v. 1. p. 1-7.

SIEBEN, A.; CLEPS JUNIOR, J. A usina hidrelétrica Estreito e a Amazônia na política energética brasileira: a desterritorialização dos camponeses ribeirinhos de Palmatuba (TO). Campo Território, v. 11, p. 433-463, 2016.

STEVAUX, J. ; LATRUBESSE, E. M. Geomorfologia Fluvial. São Paulo:Oficina de Textos, 2017.

SUGUIO K.; BIGARELLA, J. J. Ambientes fluviais. 2. ed. Curitiba: UFPR, 1990.

TOCANTINS (ESTADO) Secretaria do Planejamento e Meio Ambiente. Projeto de Gestão Ambiental Integrada da Região do Bico do Papagaio. Zoneamento Ecológico-Econômico. Análise Ambiental e Socioeconômica: Norte do Estado do Tocantins. Palmas, 2004.

VASCONCELOS, A. M.; RIBEIRO, J.A.P.; COLARES, J.Q.S.; GOMES, I.P.; FORGIARINI, L. L.; MEDEIROS, M. F. Folha Teresina SB.23. IN: SCHOBBENHAUS, C.; GONÇALVES, J. H.; SANTOS, J.O.S.; ABRAM, M.B., LEÃO NETO, R.; MATOS, G.M.M.; VIDOTTI, R. M.; RAMOS, M. A. B.; JESUS, J. D. A. DE. (EDS.). Carta Geológica do Brasil ao Milionésimo, Sistema de Informações Geográficas. Programa Geologia do Brasil. CPRM, Brasília. CD-ROM.

Recebido em Abril de 2020

Aprovado em Abril de 2020

Publicado em Fevereiro de 2021 